\title{
AN OPTIMAL ORDERING AND REPLACEMENT POLICY OF A MARKOVIAN DETERIORATION SYSTEM UNDER INCOMPLETE OBSERVATION
}

\section{PART II}

\author{
Hajime Kawai \\ University of Osaka Prefecture
}

(Received July 6, 1982; Revised June 29, 1983)

\begin{abstract}
We consider an optimal ordering and replacement policy of a discrete time Markovian deterioration system when the observation of the system is incomplete. The problem is to examine the structure of an optimal policy which minimizes the total expected discounted cost in an infinite time span. Formulating by a Markovian decision process, the optimality of a monotone policy is shown under some conditions on the deterioration system. Furthermore, some special cases are discussed.
\end{abstract}

\section{Introduction}

We treat a discrete time Markovian deterioration system, in which the degree of deterioration is quantized in many discrete states $0,1, \ldots, N$, in the order of increasing deterioration. The state 0 is a good state, i.e., the system is like new, the states $1, \ldots, N-1$ are deterioration states and the state $N$ is a failed state. In a normal operation, these states are assumed to constitute a discrete time Markovian process with an absorbing state $N$. For such a system, optimal replacement problems have been studied by Derman[2], Koleasar[6], Rosenfield[10] and others. In their works, unlimited number of spare systems for immediate replacement are assumed to be available at any time. More generally, however, we should take account of the situation in which a spare system can be obtained only by ordering and it is delivered according to some arrival rate. Kaio and Osaki[4],[5], Nakagawa and Osaki[9] have considered optimal ordering policies for a system with two states, i.e., operating and failed. Mine and Kawai[7] showed the optimality of $(S, T)-$ policy 
in which an order is placed at age $S$ and preventive replacement is made for the system the age of which is more than or equal to $T$. An optimal ordering and replacement problem of a Markovian deterioration system has been discussed in Mine and Kawai[8] under the assumption that the observation is complete. In many practical cases, it often occurs that the state of the system can not be determined exactly, i.e., the observables need not coincide with the true state of the system. In this paper, we consider an optimal ordering and replacement problem of a Markovian deterioration system under incomplete observation, and investigate the structure of an optimal policy.

\section{Model Description}

We consider a system which takes any one of $N+1$ states $0,1, \ldots, N$. The transition of the system follows the one unit time transition probabilities $p_{i j}(i, j=0,1, \ldots, N)$. The system is observed at each time but we can not determine the true state exactly. To characterize this incompleteness of observation, we introduce the conditional probenlities $r_{i \theta}(i, \theta=0,1, \ldots$, N) that the observable is $\theta$ when the system is in state $i$. Here, for simplicity of discussion, the observables are assumed to have the same state space as the one of the system, i.e., we consider the case where we make correct or incorrect identification of the true state of the system with probability $r_{i \theta}$. Each ordered spare system is delivered with arrival rate $a_{k}$ when the elapsed time from the placement of order is $k$. We assume that $\alpha_{0}=0$ and $a_{K}=1$ for some $K<\infty$.

The following costs are associated with the system.

$L=\left(L_{0}, L_{1}, \ldots, L_{N}\right)^{T}$ : operating cost where $L_{i}$ is the operating cost of the system in state $i$ per unit time.

$C=\left(C_{0}, C_{1}, \ldots, C_{N}\right)^{\mathrm{T}}:$ replacement cost where $C_{i}$ is the replacement cost of the system in state $i$. We assume that it takes one unit time to replace the system.

$A$ : ordering cost of a spare system.

$H$ : holding cost of a spare system per unit time.

For the above system, we consider an optimal ordering and replacement problem, that is, we have to determine when to order a spare system if no spare system has been ordered yet, and when to replace the system if a spare system is available in order to minimize the expected total discounted cost in an infinite time span. The problem can be regarded as a special case of 
the partially observable Markovian decision process considered by Astrom[1], Eckles[3], Sma11wood and Sondik[11], Sondik[12] and others. In the seque1, we formulate our problem by a Markovian decision process and investigate the structure of an optimal policy.

\section{Formulation by Markovian Decision Process}

We make the following definitions as for the state of the system. $x=\left(x_{0}, x_{1}, \ldots, x_{N}\right), x_{i} \geq 0, \sum_{i} x_{i}=1:$ the state probability vector of the system where $x_{i}$ is the probability that the system is in state $i$.

$y= \begin{cases}0 & \text { if an order is not placed and we have no spare system, } \\ k & \text { if a spare system is on order and the elapsed time from the } \\ & \text { placement of order is } k, 1 \leq k<\infty, \\ \infty & \text { if a spare system is available. }\end{cases}$

Then, our problem can be formulated by a Markovian decision process with the state space $\{(x, y)\}$ (Eckles[3]). In the decision process the actions to be taken are as follows.

For $(x, 0)$, we can consider the two actions, action 0 : an order is not placed, action 1 : an order is placed.

For $(x, k), 1 \leq k<\infty$, we have to wait the arrival of a spare system.

For $(x, \infty)$, we can consider the two actions.

action 2 : a replacement is not made, action 3 : a replacement is made.

We let $v(x, y)$ denote the total $\beta$-discounted cost incurred when the initial information $i s(x, y)$ and an optimal policy is employed. Then, $v(x, y)$ obey the following equations.

$$
\text { (3.1) } \begin{aligned}
v(x, 0) & =\min \left\{v_{0}(x, 0), v_{1}(x, 0)\right\}, \\
\text { (3.2) } v(x, k) & =x L+\beta\left(1-a_{k+1}\right) \sum_{\theta} q(\theta \mid x) v(T(x, \theta), k+1) \\
& +\beta a_{k+1} \sum_{\theta} q(\theta \mid x) v(T(x, \theta), \infty), \quad 1 \leq k<\infty, \\
\text { (3.3) } \quad v(x, \infty) & =\min \left\{v_{2}(x, \infty), v_{3}(x, \infty)\right\},
\end{aligned}
$$


where

$(3.4)$

$$
v_{0}(x, 0)=x L+\beta \sum_{\theta} q(\theta \mid x) v(T(x, \theta), 0)
$$

$$
\begin{aligned}
v_{1}(x, 0) & =A+x L+\beta\left(1-a_{1}\right) \sum_{\theta} q(\theta \mid x) v(T(x, \theta), 1) \\
& +\beta a_{1} \sum_{\theta} q(\theta \mid x) v(T(x, \theta), \infty)
\end{aligned}
$$

$$
v_{2}(x, \infty)=H+x L+\beta \sum_{\theta} q(\theta \mid x) v(T(x, \theta), \infty),
$$

(3.7) $v_{3}(x, \infty)=x C+\beta v\left(e_{0}, 0\right)$,

(3.8) $q(\theta \mid x)=\sum_{i, j}^{x} i_{i j}^{p} j \theta$,

$$
\begin{aligned}
T(x, \theta)= & \left(\sum_{i} x_{i} p_{i 0^{r}}{ }_{0 \theta} / q(\theta \mid x), \sum_{i} x_{i} p_{i 1}{ }^{r_{1 \theta}} / q(\theta \mid x),\right. \\
& \left.\ldots, \sum_{i} x_{i} p_{i N}{ }_{N \theta} / q(\theta \mid x)\right),
\end{aligned}
$$

(3.10) $e_{i}=\left(0_{0}, 0_{1}, \ldots, 0_{i-1}, 1_{i}, 0_{i+1}, \ldots, 0_{N}\right)$.

$v_{0}(x, 0), v_{1}(x, 0), v_{2}(x, \infty)$ and $v_{3}(x, \infty)$ correspond to the actions $0,1,2$ and 3 , respectively. Let $X(t), x(t), M(t)$ and $D(t)$ denote the state of the system, the state probability, the observable and the action at time $t$, respectively, then $q(\theta \mid x)$ and $T(x, \theta)$ imply that

(3.11) $q(\theta \mid x)=\operatorname{Pr}\{M(t+1)=\theta \mid x(t)=x, D(t) \neq 3\}$,

(3.12) $T(x, \theta)_{j}=\operatorname{Pr}\{X(t+1)=j \mid x(t)=x, M(t+1)=\theta, D(t) \neq 3\}$.

\section{Some Conditions on the Deterioration System}

We give some conditions on the behavior of the deterioration system and derive some properties of the probabilities $q(\theta \mid x)$ and $T(x, \theta)$. We assume that the following conditions hold.

C1. $p_{i j}=0$ for $i>j$

C2. $p_{i j}$ are Totally Positive of order $2\left(\mathrm{TP}_{2}\right)$, in $i, j, i . e$. ,

(4.1) $p_{j k} p_{i h}-p_{j h} p_{i k} \geqq 0$ for a11 $i<j, h<k$.

C3. $r_{i \theta}$ are $\mathrm{TP}_{2}$ in $i, \theta$, i.e., 
$(4.2)$

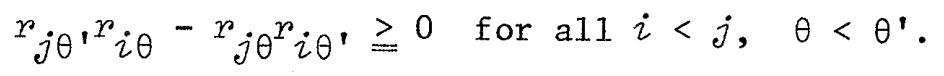

C4. $a_{k}$ is nondecreasing in $k$.

C5. We introduce the following set of vectors,

$$
\mathrm{F}=\left\{f \mid f=\left(f_{0}, f_{1}, \ldots, f_{N}\right)^{\mathrm{T}}, f_{i} \leqq f_{i+1}\right\},
$$

then $L, C \in \mathrm{F}$.

C6. $L-C \in \mathrm{F}$.

Condition 1 implies that the system can not recover its function without replacement. Condition 2 means that as the system deteriorates, it is more likely to make transition to higher states. Condition 3 reflects some tendency of observation, i.e., we can consider the case where we tend to guess the system to be in more deteriorating state as the system deteriorates. Condition 4 means that as the elapsed time after order is longer, the spare system is easier to arrive. Condition 5 shows that the operating cost and replacement cost are nondecreasing with the degree of deterioration. Condition 6 implies that the merit of replacement becomes bigger as the system deteriorates.

In the sequel, we discuss some properties of $q(\theta \mid x)$ and $T(x, \theta)$. For the purpose, we define the following relation on the set $\left\{x=\left(x_{0}, x_{1}, \ldots, x_{N}\right)\right.$, $\left.x_{i} \geq 0, \sum_{i} x_{i}=1\right\}$.

i) $x<x^{\prime}$ (TP) if and only if $x_{j}^{\prime} x_{i}-x_{i}^{\prime} x_{j} \geqq 0$ for all $i<j$.

ii) Let $w_{k}=\left(0_{0}, 0_{1}, \ldots, 0_{k-1}, 1_{k}, 1_{k+1}, \ldots, 1_{N}\right)^{\mathrm{T}}$. $x<x^{\prime}(\mathrm{ST})$ if and only if $x w_{k} \leqq x^{\prime} w_{k}$ for a11 $k=0,1, \ldots, N$.

These relations are easily shown to be partial order.

Lemma 4.1. If $x<x^{\prime}$ (TP), then $x<x^{\prime}(\mathrm{ST})$.

The proof is easily done and is omitted.

Lemma 4.2. $x<x^{\prime}$ (ST) if and only if $x f \leqq x^{\prime} f$ for all $f \in F$. For proof, see Derman[2].

We let $p_{i}=\left(p_{i 0}, p_{i 1}, \ldots, p_{i N}\right), r_{i}=\left(x_{i 0}, r_{i 1}, \ldots, r_{i N}\right)$, then $\mathrm{c} 2$ and $\mathrm{C} 3$ imply that $p_{i}<p_{j}$ (TP) and $r_{i}<r_{j}$ (TP) for $i<j$. As for $T(x, \theta)$ and $q(\theta \mid x)$, we have the following lemmas.

Lemma 4.3. Under $\mathrm{C} 2$, if $x<x^{\prime}(\mathrm{TP})$, then $T(x, \theta)<T\left(x^{\prime}, \theta\right)$ (TP) for all $\theta=0,1, \ldots, N$. 
Proof: If $x<x^{\prime}$ (TP) and $p_{i}<p_{j}$ (TP) for $i<j$, then we have that

$$
\begin{aligned}
& q(\theta \mid x) q\left(\theta \mid x^{\prime}\right)\left\{\left(T\left(x^{r}, \theta\right)\right)_{j}(T(x, \theta))_{i}-\left(T\left(x^{\prime}, \theta\right)\right)_{i}(T(x, \theta))_{j}\right\} \\
& =\sum_{k} x_{k}^{\prime} p_{k j} j_{j \theta} \sum_{k} x_{k} p_{k i}{ }_{i \theta}^{r}-\sum_{k} x_{k}^{\prime} p_{k i}{ }_{i \theta} \sum_{k} x_{k} p_{k j} j^{r} j \theta \\
& =r_{i \theta^{r}} \theta_{h \leq k} \sum_{k=k}\left(x_{k}^{\prime} x_{h}-x_{h}^{\prime \prime} x_{k}\right)\left(p_{k j} p_{h i}-p_{k i} p_{h j}\right) \geqq 0, \text { for all } i<j,
\end{aligned}
$$

which implies that $T(x, \theta)<T\left(x^{\prime}, \theta\right)$ (TP) for all $\theta$.

Lemma 4.4. Under C3, if $\theta<\theta^{\prime}$, then $T(x, \theta)<T\left(x, \theta^{\prime}\right)$ (TP) for al1 $x$.

Proof: If $\theta<\theta^{\prime}$, we have that

$$
\begin{aligned}
& q(\theta \mid x) q\left(\theta^{\prime} \mid x\right)\left\{\left(T\left(x, \theta^{\prime}\right)\right)_{j}(T(x, \theta))_{i}-\left(T\left(x, \theta^{\prime}\right)\right)_{i}(T(x, \theta))_{j}\right\} \\
& =\sum_{k} x_{k} p_{k j} j^{r} j \cdot \sum_{k} x_{k} p_{k i}{ }^{r} i \theta-\sum_{k} x_{k} p_{k i^{r}}{ }^{r} \cdot \sum_{k} x_{k} p_{k j} j^{r} \theta \\
& \left.=\sum_{h, k} x_{h} x_{k} p_{h i} p_{k j}{ }^{\left(r_{j \theta}\right.}{ }^{r}{ }_{i \theta}{ }^{-r} i{ }^{\prime}{ }^{r}{ }_{j \theta}\right) \geqq 0, \quad \text { for all } i<j \text {, }
\end{aligned}
$$

which implies that $T(x, \theta)<T\left(x, \theta^{\prime}\right)(T P)$.

Lemma 4.5. We let $q(x)=(q(0 \mid x), q(1 \mid x), \ldots, q(N \mid x))$. Under C2 and C3, if $x<x^{\prime}(\mathrm{ST})$, then $q(x)<q\left(x^{\prime}\right)$ (ST).

\section{Proof:}

(4.5) $\quad q(x) w_{k}=\sum_{i} x_{i} \sum_{j} p_{i j}{ }^{r} j w_{k}$

Since $r_{i}<r_{j}$ (ST) for $i<j$, we have that $\left(r_{0} w_{k}, r_{1} w_{k}, \ldots, r_{N} w_{k}\right)^{\mathrm{T}} \in \mathrm{F}$ for all $k$, which shows that $\left(\sum_{j} p_{0 j} j^{r} w_{k}, \sum_{j} p_{1 j^{r}} j^{w_{k}}, \ldots, \sum_{j} p_{N j} j^{r} j_{k}\right)^{T} \in$ F since $p_{i}<p_{j}$ (ST) for $i<j$. From lemma 4.2 and equation (4.5), we have that $q(x) w_{k} \leq$ $q\left(x^{\prime}\right) w_{k}$ for all $k$, which completes the proof.

\section{Structure of an Optimal Policy}

We examine the structure of an optimal ordering and replacement policy. For the purpose, we give the following lemma which plays an important role in our discussion.

Lemma 5.1. Let $g(x)$ be the function of the state probability such that if $x<x^{\prime}$ (TP), then $g(x) \leqq g\left(x^{\prime}\right)$. Under C2 and C3, if $x<x^{\prime}$ (TP), then it holds that 
(5.1) $\quad \sum_{\theta} q(\theta \mid x) g(T(x, \theta)) \leqq \sum_{\theta} q\left(\theta \mid x^{\prime}\right) g\left(T\left(x^{\prime}, \theta\right)\right)$.

Proof: From lemmas 4.3 and 4.4 , we have that

(5.2) $T(x, \theta)<T\left(x^{\prime}, \theta\right)(T P)$ for all $\theta$,

and

(5.3) $T(x, \theta)<T\left(x, \theta^{\wedge}\right)(T P)$ for all $\theta<\theta^{\prime}$ and $x$.

Equations (5.2) and (5.3) show that

(5.4) $g(T(x, \theta)) \leqq g\left(T\left(x^{\prime}, \theta\right)\right)$ for a11 $\theta$,

and

(5.5) $\quad(g(T(x, 0)), g(T(x, 1)), \ldots, g(T(x, N)))^{T} \in \mathrm{F}$ for all $x$.

Froom lemma 4.5, we have that

(5.6) $\quad q(x)<q\left(x^{\prime}\right)(\mathrm{ST})$

Using equations $(5.4),(5.5),(5.6)$ and lemma 4.2 , we have that

(5.7) $\quad \sum_{\theta} q\left(\theta \mid x^{\prime}\right) g\left(T\left(x^{\prime}, \theta\right)\right) \geqq \sum_{\theta} q\left(\theta \mid x^{\prime}\right) g(T(x, \theta)) \geqq \sum_{\theta} q(\theta \mid x) g(T(x, \theta))$,

which completes the proof.

With respect to the optimal cost $v(x, k), k=0,1, \ldots, \infty$, we have the following lemma.

Lemma 5.2. Under $\mathrm{C} 1$ through $\mathrm{C} 6$, if $x<x^{\prime}$ (TP), then it holds that

$$
v(x, k) \leq v\left(x^{\prime}, k\right) \text { for } k=0,1, \ldots, \infty,
$$

and

(5.9) $v(x, h)-v(x, k) \leqq v\left(x^{\prime}, h\right)-v\left(x^{\prime}, k\right)$, for $0 \leqq h<k \leqq \infty$.

Proof: The proof is done through induction. Let $v^{n}(x, k)$ denote the optimal $n$-period costs. Then

(5.10) $v^{1}(x, k)=x L, 0 \leq k<\infty$,

(5.11) $v^{1}(x, \infty)=\min \{H+x L, x C\}$,

and for $n \geqq 2$,

(5.12) $v^{n}(x, 0)=\min \left\{v_{0}^{n}(x, 0), v_{1}^{n}(x, 0)\right\}$,

(5.13) $v^{n}(x, k)=x L+\beta\left(1-a_{k+1}\right) \sum_{\theta} q(\theta \mid x) v^{n-1}(T(x, \theta), k+1)$

$+\beta a_{k+1} \sum_{\theta} q(\theta \mid x) v^{n-1}(T(x, \theta), \infty), \quad 1 \leqq k<\infty$ 
$(5.14)$

$$
v^{n}(x, \infty)=\min \left\{v_{2}^{n}(x, \infty), v_{3}^{n}(x, \infty)\right\},
$$

where

$$
\begin{aligned}
v_{0}^{n}(x, 0) & =x L+\beta \sum_{\theta} q(\theta \mid x) v^{n-1}(T(x, \theta), 0), \\
v_{1}^{n}(x, 0) & =A+x L+\beta\left(1-\alpha_{1}\right) \sum_{\theta} q(\theta \mid x) v^{n-1}(T(x, \theta), 1) \\
& +\beta a_{1} \sum_{\theta} q(\theta \mid x) v^{n-1}(T(x, \theta), \infty),
\end{aligned}
$$

$$
\begin{aligned}
& v_{2}^{n}(x, \infty)=H+x L+\beta \sum_{\theta} q(\theta \mid x) v^{n-1}(T(x, \theta), \infty), \\
& v_{3}^{n}(x, \infty)=x C+\beta v^{n-1}\left(e_{0}, 0\right) .
\end{aligned}
$$

From C5, C6, lenmas 4.1 and 4.2, it is easily seen that if $x<x^{\prime}$ (TP), then $v^{1}(x, k) \leqq v^{1}\left(x^{\prime}, k\right)$ for all $k$ and $v^{1}(x, h)-v^{1}(x, k) \leqq v^{1}\left(x^{\prime}, h\right)-v^{1}\left(x^{\prime}, k\right)$ for $0 \leqq h<k \leqq \infty$. For simplicity of expression, we abbreviate

$$
q=q(\theta \mid x), q^{\prime}=q\left(\theta \mid x^{\prime}\right), v(k)=v^{n-1}(T(x, \theta), k) \text { and } v^{\prime}(k)=v^{n-1}\left(T\left(x^{\prime}, \theta\right), k\right) \text {. }
$$

We assume that if $x<x^{\prime}$ (TP), then

(5.19) $v(k) \leqq v^{\prime}(k), \quad k=0,1, \ldots, \infty$,

(5.20) $v(h)-v(k) \leq v^{\prime}(h)-v^{\prime}(k)$, for $0 \leq h<k \leq \infty$.

From lemma 5.1 and equations (5.12)-(5.20), it is shown that if $x<x^{\prime}$ (TP), then $v^{n}(x, k) \leq v^{n}\left(x^{\prime}, k\right)$ for all $k$. From now on, we show that if $x<x^{\prime}$ (TP), then $v^{n}(x, h)-v^{n}(x, k) \leqq v^{n}\left(x^{\prime}, h\right)-v^{n}\left(x^{\prime}, k\right)$ for $0 \leqq h<k \leqq \infty$. For the proof, it is sufficient to show that the following three equations hold if $x<x^{\prime}$ (TP).

(5.21) $v^{n}(x, 0)-v^{n}(x, k) \leqq v^{n}\left(x^{\prime}, 0\right)-v^{n}\left(x^{\prime}, k\right), \quad 1 \leqq k<\infty$,

(5.22) $v^{n}(x, k)-v^{n}(x, \infty) \leqq v^{n}\left(x^{\prime}, k\right)-v^{n}\left(x^{\prime}, \infty\right), \quad 1 \leq k<\infty$,

(5.23) $v^{n}(x, h)-v^{n}(x, k) \leqq v^{n}\left(x^{\prime}, h\right)-v^{n}\left(x^{\prime}, k\right), \quad 1 \leqq h<k<\infty$.

It should be noted that equations (5.21) and (5.22) imply that

(5.24) $v^{n}(x, 0)-v^{n}(x, \infty) \leqq v^{n}\left(x^{\prime}, 0\right)-v^{n}\left(x^{\prime}, \infty\right)$.

We let $D^{n}(x, k)$ denote the action which gives $v^{n}(x, k)$, e.g., if $D^{n}(x, \infty)=3$, then we should replace the system by a spare system.

i) Proof of equation (5.21). We consider the two cases as for $D\left(x^{\prime}, 0\right)$ : (1) $D^{n}\left(x^{\prime}, 0\right)=0$, (2) $D^{n}\left(x^{\prime}, 0\right)=1$.

Case (1). From equations (5.12)-(5.16), lemma 5.1 and the assumption of induction, we have that 
$(5.25)$

$$
\begin{aligned}
& \left\{v^{n}\left(x^{\prime}, 0\right)-v^{n}\left(x^{\prime}, k\right)-\left(v^{n}(x, 0)-v^{n}(x, k)\right)\right\} B^{-1} \\
& \geqq\left\{v_{0}^{n}\left(x^{\prime}, 0\right)-v^{n}\left(x^{\prime}, k\right)-v_{0}^{n}(x, 0)+v^{n}(x, k)\right\} \beta^{-1} \\
& =\sum_{\theta} q^{\prime} v^{\prime}(0)-\left(1-a_{k+1}\right) \sum_{\theta} q^{\prime} v^{\prime}(k+1)-a_{k+1} \sum_{\theta} q^{\prime} v^{\prime}(\infty) \\
& -\sum_{\theta} q v(0)+\left(1-a_{k+1}\right) \sum_{\theta} q v(k+1)+a_{k+1} \sum_{\theta} q v(\infty) \\
& =\sum_{\theta} q^{\prime}\left(v^{\prime}(0)-v^{\prime}(k+1)\right)-\sum_{\theta} q(v(0)-v(k+1))+a_{k+1} \sum_{\theta} q^{\prime}\left(v^{\prime}(k+1)-v^{\prime}(\infty)\right) \\
& -a_{k+1} \sum_{\theta} q(v(k+1)-v(\infty)) \geqq 0 .
\end{aligned}
$$

Case(2). From $\mathrm{C} 4$, we have that

$$
\begin{aligned}
& \left\{v^{n}\left(x^{\prime}, 0\right)-v^{n}\left(x^{\prime}, k\right)-\left(v^{n}(x, 0)-v^{n}(x, k)\right)\right\} B^{-1} \\
& \geqq\left\{v_{1}^{n}\left(x^{\prime}, 0\right)-v^{n}\left(x^{\prime}, k\right)-v_{1}^{n}(x, 0)+v^{n}(x, k)\right\} B^{-1} \\
& =\left(1-a_{1}\right) \sum_{\theta} q^{\prime}\left(v^{\prime}(1)-v^{\prime}(k+1)\right)-\left(1-a_{1}\right) \sum_{\theta} q(v(1)-v(k+1)) \\
& +\left(a_{k+1}-a_{1}\right) \sum_{\theta} q^{\prime}\left(v^{\prime}(k+1)-v^{\prime}(\infty)\right)-\left(a_{k+1}-a_{1}\right) \sum_{\theta} q(v(k+1)-v(\infty)) \geqq 0 .
\end{aligned}
$$

Hence, from equations (5.25) and (5.26), equation (5.21) holds.

ii) Proof of equation (5.22). We consider the two cases as for $D^{n}(x, \infty)$ : (1) $D^{n}(x, \infty)=2$, (2) $D^{n}(x, \infty)=3$.

Case (1). From equations (5.1.3), (5.14), (5.17), lemma 5.1 and the assumption of induction, we have that

$$
\begin{aligned}
& \left\{v^{n}\left(x^{\prime}, k\right)-v^{n}\left(x^{\prime}, \infty\right)-\left(v^{n}(x, k)-v^{n}(x, \infty)\right)\right\} \beta^{-1} \\
& \geqq\left\{v^{n}\left(x^{\prime}, k\right)-v_{2}^{n}\left(x^{\prime}, \infty\right)-v^{n}(x, k)+v_{2}^{n}(x, \infty)\right\} \beta^{-1} \\
& =\left(1-\alpha_{k+1}\right)\left\{\sum_{\theta} q^{\prime}\left(v^{\prime}(k+1)-v^{\prime}(\infty)\right)-\sum_{\theta} q(v(k+1)-v(\infty))\right\} \geqq 0 .
\end{aligned}
$$

Case (2). From $\mathrm{C} 6$ and 1emma 4.2, we have that

$$
\text { (5.28) } \begin{aligned}
& v^{n}\left(x^{\prime}, k\right)-v^{n}\left(x^{\prime}, \infty\right)-\left(v^{n}(x, k)-v^{n}(x, \infty)\right) \\
& \geq v^{n}\left(x^{\prime}, k\right)-v_{3}^{n}\left(x^{\prime}, \infty\right)-v^{n}(x, k)+v_{3}^{n}(x, \infty) \\
& =x^{\prime}(L-C)-x(L-C)+\beta\left(1-a_{k+1}\right)\left(\sum_{\theta} q^{\prime} v^{\prime}(k+1)-\sum_{\theta} q v(k+1)\right) \\
& +\beta a_{k+1}\left(\sum_{\theta} q^{\prime} v^{\prime}(\infty)-\sum_{\theta} q v(\infty)\right) \geq 0 .
\end{aligned}
$$


Hence, from equations (5.27) and (5.28), equation (5.22) holds.

iii) Proof of equation (5.23). From C4, equation (5.13), lemma 5.1 and the assumption of induction, we have that for $h<k$,

$$
\begin{aligned}
(5.29) & \left\{v^{n}\left(x^{\prime}, h\right)-v^{n}\left(x^{\prime}, k\right)-\left(v^{n}(x, h)-v^{n}(x, k)\right)\right\} \beta^{-1} \\
& =\left(1-a_{h+1}\right)\left\{\sum_{\theta} q^{\prime}\left(v^{\prime}(h+1)-v^{\prime}(k+1)\right)-\sum_{\theta} q(v(h+1)-v(k+1))\right\} \\
& +\left(a_{k+1}-a_{h+1}\right)\left\{\sum_{\theta} q^{\prime}\left(v^{\prime}(k+1)-v^{\prime}(\infty)\right)-\sum_{\theta} q(v(k+1)-v(\infty))\right\} \geqq 0 .
\end{aligned}
$$

Hence, equation (5.23) holds.

Therefore, $v^{n}(x, h)-v^{n}(x, k) \leqq v^{n}\left(x^{\prime}, h\right)-v^{n}\left(x^{\prime}, k\right)$ holds for all $0 \leqq h<k \leqq \infty$ and $n$. Since

(5.30) $\lim _{n \rightarrow \infty} v^{n}(x, k)=v(x, k)$

(Eckles[3]), we have that if $x<x^{\prime}(\mathrm{TP})$, then $v(x, k) \leqq v\left(x^{\prime}, k\right)$ for all $k$, $v(x, h)-v(x, k) \leqq v\left(x^{\prime}, h\right)-v\left(x^{\prime}, k\right)$ for $0 \leqq h<k \leqq \infty$. This completes the proof.

Going back to equations $(3.1)-(3.7)$ and subtracting $v_{1}(x, 0)$ from $v_{0}(x, 0)$, we have that

$$
\begin{aligned}
v_{0}(x, 0)-v_{1}(x, 0) & =-A+\beta \sum_{\theta} q(\theta \mid x)\{v(T(x, \theta), 0)-v(T(x, \theta), 1)\} \\
& +\beta \alpha_{1} \sum_{\theta} q(\theta \mid x)\{v(T(x, \theta), 1)-v(T(x, \theta), \infty)\} .
\end{aligned}
$$

Using lemmas 5.1 and 5.2 , we can show that for $x<x^{\prime}$ (TP),

$$
v_{0}(x, 0)-v_{1}(x, 0) \leqq v_{0}\left(x^{\prime}, 0\right)-v_{1}\left(x^{\prime}, 0\right) \text {. }
$$

Subtracting $v_{3}(x, \infty)$ from $v_{2}(x, \infty)$, we have that

$$
v_{2}(x, \infty)-v_{3}(x, \infty)=H+x(L-C)+\beta \sum_{\theta} q(\theta \mid x) v(T(x, \theta), \infty)-\beta v\left(e_{0}, 0\right) .
$$

Using lemmas 5.1 and 5.2, we can show that for $x<x^{\prime}$ (TP),

$$
v_{2}(x, \infty)-v_{3}(x, \infty) \leq v_{2}\left(x^{\prime}, \infty\right)-v_{3}\left(x^{\prime}, \infty\right)
$$

Equations (5.32) and (5.34) gives us the following theorem as for an optimal ordering and replacement policy.

Theorem 5.1. We let $D(x, k)$ denote an optimal action for $(x, k)$. Under $\mathrm{Cl}$ through $\mathrm{C} 6$, if $x<x^{\prime}(\mathrm{TP})$, then 
$(5.35) \quad D(x, 0) \leqq D\left(x^{\prime}, 0\right)$ and $D(x, \infty) \leq D\left(x^{\prime}, \infty\right)$

When $N=2$, the state space is $\left\{\left(\left(x_{1}, x_{2}\right), k\right) \mid x_{1}, x_{2} \geq 0, x_{1}+x_{2} \leqq 1\right\}$, and is divided into two regions under an optimal ordering and replacement policy as shown in Fig.1.
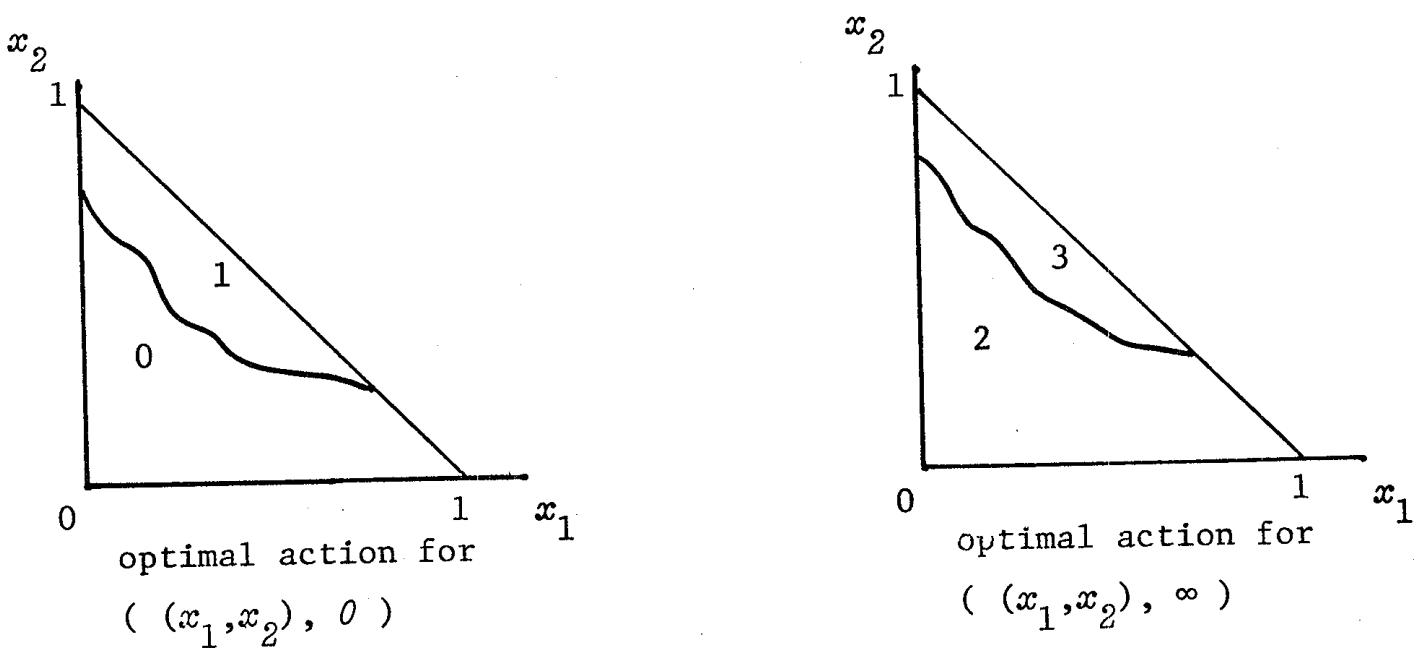

Fig.1. Optimal policy when $N=2$.

\section{Some Special Cases}

We discuss the structure of an optimal policy in some special cases.

Case 1). No information case.

We consider the case where the observables gives us no information about the true state of the system. This implies that

(6.1) $\quad r_{i \theta}=r_{\theta}$ for all $i$

We let $P_{i j}(t)$ denote the $t$-unit time transition probability from state $i$ to state $j$ associated with the state of the system, i.e., they are given by

$$
P_{i j}(0)=\delta_{i j}\left(\delta_{i j} \text { is Kronecker's delta }\right) \text {, }
$$

$$
P_{i j}(t+1)=\sum_{k} P_{i k}(t) p_{k j}
$$

We assume to start with the information $\left(e_{0}, 0\right)$ ( it should be noted that 
immediately after replacement, we have always the information $\left.\left(e_{0}, 0\right)\right)$, then from equations $(3.8),(3.9),(6.1)$ and $(6.2)$, it holds that

$$
\begin{aligned}
& \text { (6.3) } T\left(e_{0}, \theta\right)=P_{0}(1), \\
& \text { (6.4) } T\left(P_{0}(t), \theta\right)=P_{0}(t+1),
\end{aligned}
$$

where

$$
P_{0}(t)=\left(P_{00}(t), P_{01}(t), \ldots, P_{O N}(t)\right)
$$

Equations (6.3) and (6.4) imply that the set of the state probability is given by

(6.6) $\{x\}=\left\{P_{0}(t), t=0,1, \ldots\right\}$.

It is easily seen that $r_{i \theta}$ satisfy $\mathrm{C} 2$. Further, under $\mathrm{C} 1$ and $\mathrm{C} 3, P_{i j}(t)$ are shown to be $\mathrm{TP}_{2}$ in $j, t$ (Rosenfield[10]). Hence, we have that

(6.7) $\quad P_{0}(t)<P_{0}(t+1)(\mathrm{TP})$,

which also implies that the relation <(TP) is total order on the set $\{x\}$. From equations $(6.6),(6.7)$ and lemma 5.1 , we can conclude that there exists an optimal policy has the form of $(S, T)$-policy.

Case 2). Complete information case.

We consider the case where the observation is always correct, i.e., (6.8) $r_{i \theta}=\delta_{i \theta}$.

From equations $(3.8),(3.9)$ and $(6.8)$, we have that

(6.9) $T(x, i)=e_{i}, i=0,1, \ldots, N$.

Hence, if we start with the information $\left(e_{0}, 0\right)$, then the set of the state probability is given by

(6.10) $\{x\}=\left\{e_{i}, i=0,1, \ldots, N\right\}$

It is easily seen that $r_{i \theta}$ satisfy $\mathrm{C} 3$. Further, it is clear that $e_{i}<e_{j}$ (TP) for $i<j$, which also implies that the relation <(TP) is total order on the set $\{x\}$. Hence, from theorem 5.1, we can conclude that there exists an optimal policy which has the form of $(m, M)$-policy. This policy means that each order is placed if and only if the system enters the states $m, m+1, \ldots, N$ and each replacement is made if and only if the system enters the states $M, \ldots, N$ when a spare system is available.

Case 3). Two states case.

We consider the case where the system has only two states, i.e., a good state and a failed state. In this case, the behavior of the system and the 
accurancy of observation are characterized by

$$
p_{00}+p_{01}=1, \quad p_{11}=1, r_{00}+r_{01}=1, \quad r_{10}+r_{11}=1 \text {. }
$$

The state probability can be expressed by the failure probability $g$, i.e., $\{x\}=\{(1-g, g), 0 \leqq g \leqq 1\}$. From equation (6.11), we have that

$$
p_{11} p_{00}-p_{10^{p}} p_{01}=p_{11} p_{00} \geq 0
$$

(6.13) $r_{11} r_{00}-r_{10} r_{01}=r_{00}+r_{11}-1$.

Hence, $\mathrm{C} 2$ holds and if $r_{00} \geq 0.5, r_{11} \geqq 0.5$, then $\mathrm{C} 3$ holds. This condition for $r_{i \theta}$ reflects some real situation, i.e., it is natural to consider that the probability of correct observation is greater than the probability of incorrect observation. For the relation <(TP), it is clear that (6.14) $x=(1-g, g)<x^{\prime}=\left(1-g^{\prime}, g^{\prime}\right)(\mathrm{TP}) \leftrightarrow g \leqq g^{\prime} \leftrightarrow x<x^{\prime}$ (ST).

Therefore, from theorem 5.1, we can conculde that there exists an optimal policy which has the form of $(g, G)$-policy. This policy means that each order is placed if and only if the failure probability of the system is greater than or equal to $g$ and each replacement is made if and only if the failure probability is greater than or equal to $G$ when a spare system is available.

In case 1), consider the following weaker condition than $\mathrm{C} 2$, (6.15) C2' $p_{i}=\left(p_{i 0}, p_{i 1}, \ldots, p_{i N}\right)<p_{j}=\left(p_{j 0}, p_{j 1}, \ldots, p_{j N}\right)(\mathrm{ST})$ for $i<j$, then it can be easily shown that (6.16) $P_{0}(t)<P_{0}(t+1)(\mathrm{ST})$

By a similar discussion as in lemmas 4.4, 5.1, 5.2 and theorem 5.1 , we can show the optimality of $(S, T)$-policy under the condition $C 2^{\prime}$.

In case 2 ), it is clear that $e_{i}<e_{j}$ (ST) for $i<j$. Hence, as in case 1 ), we can obtain the result in this case under the condition $\mathrm{C}^{\prime}$ '.

\section{Conclusion}

In this paper, we have discussed an optimal ordering and replacement problem of a discrete time Markovian deterioration system under incomplete observation. The problem is formulated by a Markovian decision process and the optimality of a monotone policy has been shown under some reasonable conditions on physical and economic aspects of the deterioration system. The model discussed here contains the usual replacement model, ordering and replacement model under complete observation as special cases. In our model, it is assumed 
that only one spare system can be kept in inventory. In more general cases, however, this assumption should be relaxed, that is, any number of spares are allowed. It is also assumed that we can observe the system at any time without any cost. But in many practical situation, observation is costly. Hence, the control problem of the time interval between observations should be studied. These problems will be treated in future works.

\section{References}

[1] Astrom, K.J.: Optimal Control of Markovian Processes with Incomplete State Observation. Joumal of Mathematical Analysis and Applications, vo1.10 (1965), 174-205.

[2] Derman, C.: Finite State Markovian Decision Processes. Academic Press, 1970 .

[3] Eckles, J.E.: Optimum Maintenance with Incomplete Information. Operations Research, vo1.16 (1968), 1058-1067.

[4] Kaio, N. and Osaki, S.: Optimum Ordering Policies with Two kinds of Lead Times and Nonlinear Ordering Costs. International Journal of System Science, vol.9 (1978), 265-272.

[5] Kaio, N. and Osaki, S.: Discrete-time Ordering Policies. IEEE Transactions on Reliability, vol.R-28 (1979), 405-406.

[6] Koleasar, P.: Minimum Cost Replacement under Markovian Deterioration. Management Science, vol.12 (1973), 694-705.

[7] Mine, H. and Kawai, H.: Optimal Ordering and Replacement for a 1-unit System. IEEE Transactions on Reliability, vol.R-26 (1977), 273-276.

[8] Mine, H. and Kawai, H.: A Note on Ordering and Replacement Policy. Abstracts of Autum Research Conference of the Operations Research Society of Japan, 1981, (in Japanese).

[9] Nakagawa, T. and Osaki, S.: Optimum Ordering Policies with Lead Time for an Operating Unit. Revue Francaise d'Automatique, Informatique et Recherche Operationnelle, vol.12 (1978), 383-393.

[10] Rosenfield, D.: Markovian Deterioration with Uncertain Information. Operations Research, vol.24 (1976), 145-155.

[11] Sma11wood, R.D. and Sondik, E.J.: The Optimal Control of Pratially Observable Markov Processes over an Infinite Horizon. Operations Research, vol.21 (1973), 1071-1088.

[12] Sondik, E.J.: The Optimal Control of Partially Observable Markov 
Processes over the Infinite Horizon: Discounted Costs. Operations Research, vol.26 (1978), 282-303.

Hajime KAWAI: Department of Business Administration, School of Economics, University of Osaka Prefecture, Sakai, Osaka, 591, Japan. 


\title{
アブストラクト
}

不完全観測の下でのマルコフ的劣化システム の最適発注・取替政策 II

\author{
大阪府立大学 河 合
}

離散時間マルコフ的劣化システムの不完全観測の下での最適発注・取替問題を議論する。シスデ 厶は, 0 : 新品, $1, \cdots \cdots, N-1$ 少化, $N$ : 故障, の $N+1$ 個の状態をとり，乙れらは状態 $N$ を吸 収状態とする推移確率 $p_{i j}$ をむつマルコフ過程をなすとする。さらに，システムは常時観測され ているが，観測結果は必ずしもシステムの状態と一致しない状況を考える。観測結果の集合は簡 単化のためシステムの状態集合で同じであるとし，観測の不完全さは, システムが状態 $i$ にる とき観測結果が $\theta$ である確率 $r_{i} \theta$ で規定されるあのとする。乙のようなシステムに対し，取替え のためのスペアシステムは，ある調達時間を伴なう注文によってのみ手に入るとしたとき，我々 は，注文していなくてスペアがないときは，決定 0 : 注文しない，決定 1 : 注文する，のいずれ かを選び，スペアがあるときは，決定 2 ：取替えずに動作を続ける，決定 3 ：取替える，のいず れかを選ぶ。問題は，総期待割引費用を最小にする意味での最適政策の構造を調べることである。

乙の決定問題は, Partially Observable Markov Decision Process の理論を用い,

$$
\begin{aligned}
& x=\left(x_{0}, x_{1}, \cdots \cdots, x_{N}\right), x_{i} \geqq 0, \Sigma_{i} x_{i}=1: \text { システムの状態確率ベクトル } \\
& y=\left\{\begin{array}{c}
0: \text { 注文していなくて }, \text { スペアあないとき } \\
k: \text { 注文中であり, 注文品が } k \text { 期間到着していないとき } \\
\quad \text { (調達時間は一期以上, 有限とする }) \\
\infty: \text { スペアがあるとき }
\end{array}\right.
\end{aligned}
$$

とすると, 状態空間 $\{(x, y)\}$, 決定空間 $\{0,1,2,3\}$ を時つマルコフ決定過程として 定式化される。システムの物理的，経済的側面からのいくつかの妥当な条件の下で，ある単調な 構造を持つ最啇政策の存在が示される。すなわち, $\mathrm{D}(x, y)$ で状態 $(x, y)$ 亿対する最適な決 定を示し, 集合 $\{x\}$ の上で半順序 $<(\mathrm{TP})$ を, $x<x^{\prime}(\mathrm{TP}):$ すべての $i<j に$ 対し, $x_{j}^{\prime} x_{i}-x_{i}^{\prime} x_{j} \geqq 0$ で定義すると, $x<x^{\prime}(\mathrm{TP})$ ならば, $\mathrm{D}(x, 0) \leqq \mathrm{D}\left(x^{\prime}, 0\right), \mathrm{D}(x, \infty)$ $\leqq \mathrm{D}\left(x^{\prime}, \infty\right)$ となる。最後に 2,3 の特別な場合，すなわち，観測がシステムの状態関する何ら らの情報む与えない場合，観測が完全な場合，などについて考察する。 